\title{
Removal of siloxanes from biogas using acetylated silica gel as adsorbent
}

\author{
Yu-Heng Liu ${ }^{1,2} \cdot$ Ze-You Meng $^{1} \cdot$ Ji-Ye Wang $^{1} \cdot$ Yan-Fei Dong ${ }^{1} \cdot$ Zi-Chuan Ma $^{1}$
}

Received: 10 September 2018 / Published online: 21 June 2019

(c) The Author(s) 2019

\begin{abstract}
Biogas can be used as an alternative energy source for producing heat and electricity; however, volatile methylsiloxanes (VOSiC) present in biogas can severely damage heat exchangers, turbines and gas engines. Consequently, efficient removal of VOSiC from biogas that is used as a biofuel is required. In this work, acetylated silica gel (Ac@SG) was synthesized, via treatment of microporous silica gel (SG) with acetic anhydride as an adsorbent, for removal of VOSiC from biogas, and characterized with XRD, SEM-EDS, $\mathrm{N}_{2}$-BET and FT-IR. This Ac@ SG adsorbent exhibited a meso-/microporous structure and hydrophobic surface, indicating it was a more efficient adsorbent for removing hexamethyldisiloxane (L2) and octamethylcyclotetrasiloxane (D4) from biogas samples than conventional SG. It was found that the adsorption capacities of Ac@SG reached $304 \mathrm{mg} \mathrm{L2/g}$ for hexamethyldisiloxane and $916 \mathrm{mg}$ D4/g for octamethylcyclotetrasiloxane at lower temperatures in the experimental range, and water had no significant effect on its absorption efficiency. The used Ac@SG could be easily regenerated by heating it at $110^{\circ} \mathrm{C}$, and the adsorption capacity of recycled Ac@SG for hexamethyldisiloxane and octamethylcyclotetrasiloxane was kept constant in four recycle adsorption experiments.
\end{abstract}

Keywords Siloxanes $\cdot$ Biogas $\cdot$ Acetylated silica gel $\cdot$ Adsorption $\cdot$ Removal of the siloxanes

\section{Introduction}

Climate change and the end of the 'cheap oil' era have prompted investigations into the technical and financial resources required to replace fossil fuels with renewable energy sources (de Arespacochaga et al. 2014), such as the waste materials from industrial and domestic sources available as potential energy sources. Biogas is produced by the anaerobic digestion of organic matter in landfill and

Edited by Xiu-Qin Zhu and Xiu-Qiu Peng

Handling editor: Runduo Zhang

Electronic supplementary material The online version of this article (doi:https://doi.org/10.1007/s12182-019-0336-4) contains supplementary material, which is available to authorized users.

Zi-Chuan Ma

mazc@hebtu.edu.cn

1 College of Chemistry and Material Science, Hebei Normal University, Shijiazhuang 050024, Hebei, China

2 College of Pharmaceutical Sciences, Hebei Medical University, Shijiazhuang 050017, Hebei, China sewage plants. Biogas is primarily comprised of methane $\mathrm{CH}_{4}(50 \%-70 \%)$ and carbon dioxide $\mathrm{CO}_{2}(30 \%-50 \%)$, as well as trace amounts of other components, such as hydrogen sulfide, halogenated compounds, volatile organic compounds (VOCs) and siloxanes (Kougias and Angelidaki 2018; Devia and Subrenat 2013). Currently, the use of biogas as a renewable energy sources is complicated due to the presence of siloxane contaminants, which are transformed into microcrystalline $\mathrm{SiO}_{2}$ at high temperatures, whose abrasiveness and thermoelectric insulating properties can severely damage heat exchangers, turbines and gas engines (Turkin et al. 2014; Lee and Rittmann 2016; Allen et al. 1997). Consequently, it is necessary to reduce the amount of siloxanes in biogas below a threshold level (e.g., $10 \mathrm{mg}$ siloxane $/ \mathrm{m}^{3}$ of methane) if it is to be used as a biofuel for energy applications (Devia and Subrenat 2013; Lee and Rittmann 2016; Dewil et al. 2006). Several methods are used in industry to remove siloxanes from biogas, including adsorption by porous materials (Sigot et al. 2015; Jiang et al. 2016; Jafari et al. 2016) and oils (Devia and Subrenat 2013); however, their performance is often unsatisfactory, because they employ expensive or non-recyclable materials, involve long treatment time and high energy consumption, 
and only afford low saturation adsorption levels (Kajolinna et al. 2015; Ajhar et al. 2010). Therefore, it is necessary to find a more effective method that employs recyclable materials to remove siloxanes from biogas so that it can be used as a renewable fuel. Adsorption techniques are one of the simplest techniques used for gas purification (Ajhar et al. 2010), with silica gel (SG) often used to adsorb organic compounds, such as alkanes, toluene, 2,4,6-trinitrotoluene and herbicides (Machin and Golding 1987; Sui et al. 2017a, b; An et al. 2009; Koner et al. 2013). In this work, acetylated silica gel (Ac@SG) was studied as an adsorbent for removal of siloxanes from biogas, and it was found to exhibit better adsorption properties for hexamethyldisiloxane and octamethylcyclotetrasiloxane than pristine SG.

\section{Materials and methods}

\subsection{Chemicals and materials}

All the chemicals and reagents used in this study were of analytical grade. Microporous silica gel (SG) was obtained from Liang Chen Silicon Material Co. Limited, Anhui Province, China. Hexamethyldisiloxane (L2, 99\%) and octamethylcyclotetrasiloxane (D4, 99\%) used as representative siloxanes for adsorption experiments were obtained from Tokyo Chemical Industry Co. Limited, Tokyo, Japan. Acetic anhydride was purchased from Rionlon Bohua Pharmaceutical \& Chemical Co. Limited, Tianjin, China.

\subsection{Preparation of acetylated silica gel}

\subsubsection{Activation of silica gel}

Silica gel $(50 \mathrm{~g})$ was refluxed with an excess of $\mathrm{HCl}(18.5 \%$, $\mathrm{v} / \mathrm{v}$ ) solution for $12 \mathrm{~h}$, then filtered off and washed with deionized water until no detectable chloride ion could be found in the filtrate. The resultant activated silica was then dried at $150{ }^{\circ} \mathrm{C}$ for $12 \mathrm{~h}$ to remove any adsorbed water from its surface (Ahmed 2014; Uruş et al. 2013; Çimen et al. 2015).

\subsubsection{Modification of silica gel with acetic anhydride}

Acetic anhydride $(7.4 \mathrm{~mL})$ was added to activated silica gel $(3.0 \mathrm{~g})$ at room temperature, and the mixture was then stirred at $90{ }^{\circ} \mathrm{C}$ for $10 \mathrm{~h}$. The mixture was then separated by filtration and the solid soaked in deionized water for $30 \mathrm{~min}$, before being washed with deionized water until the washings were neutral. The resultant solid was then dried in an oven at $110{ }^{\circ} \mathrm{C}$ for $12 \mathrm{~h}$ to afford the desired acetylated silica gel (Ac@SG) (Damja and Eaborn 1985; Eaborn et al. 1988).

\subsection{Characterization methods}

The surface morphology of adsorbents was studied using a Hitachi S-4800 scanning electron microscope (SEM). Elemental compositions were determined on the SEM, which was equipped with an INCA 350 energy-dispersive spectrometer (EDS) operating at $133 \mathrm{eV}$ resolution at $5.9 \mathrm{KeV}$. Nitrogen adsorption/desorption isotherms were measured at $-196{ }^{\circ} \mathrm{C}$ using an automatic surface area and pore analyzer (Kubo $\times 1000$, Beijing Builder Co., China), with all samples being degassed at $200{ }^{\circ} \mathrm{C}$ for $3 \mathrm{~h}$ before analysis. Specific surface areas $\left(S_{\mathrm{BET}}\right)$ and micropore volumes $\left(V_{\text {micro }}\right)$ were calculated using the Brunauer-Emmett-Teller (BET) equation and Dubinin-Radushkevich (DR) method, respectively. The total pore volume $\left(V_{\mathrm{t}}\right)$ was estimated from the liquid volume of $\mathrm{N}_{2}$ adsorbed at a relative pressure of 0.99 . Pore size distribution curves were obtained using the Barrett-Joyner-Halenda (BJH) method. X-ray diffraction (XRD) analysis was carried out using a Bruker D8 ADVANCE $\mathrm{X}$-ray diffractometer. Fourier transform infrared (FT-IR) spectra were recorded over a range of $4000-400 \mathrm{~cm}^{-1}$ with $\mathrm{KBr}$ pellets using a Bruker Tensor 27 spectrometer (Bruker Optics Co., Germany).

\subsection{Siloxane adsorption setup and procedure}

Concentrations of siloxanes (L2 and D4) were measured using gas chromatography employing a hydrogen flame ionization detector (GC/FID). The adsorption measurement apparatus used for evaluation of samples is shown in Fig. 1. Nitrogen flow containing a defined percentage of L2 or D4 was passed through a quartz tube $(8 \mathrm{~mm})$ containing an appropriate bed height of adsorbent. The volume ratio of a model gas to $\mathrm{N}_{2}$ was obtained by mixing two nitrogen flows from a cylinder $(99.9 \%)$. The first flow, F1, was bubbled through a bottle filled with liquid siloxane (L2 or D4), with the resultant stream enriched in vaporized siloxane, then mixed and diluted by the F2 nitrogen stream. The F1 and F2 flows were controlled using two mass flow controllers, MFC1 (0-100 mL/min) and MFC2 (0-100 mL/min), which were calibrated separately using the L2-in- $\mathrm{N}_{2}$ and D4-in- $\mathrm{N}_{2}$ feed gas. This enabled a stable concentration of siloxane gas to be obtained using this mixing setup, with the concentration of L2 and D4 in the model gas adjusted to 83.8 and $7.9 \mathrm{mg} / \mathrm{L}$, respectively.

Preliminary measurements were taken by passing the input stream through an adsorbent before every test in order to adjust the concentration level of the model gas. The mixed stream was then sent to the adsorption bed, with the exit gas then sent to the GC/FID for analysis. The adsorption column was operated until the siloxane outlet concentration matched the inlet concentration (i.e., bed exhaustion), with 
Fig. 1 Schematic of the siloxane adsorption measurement apparatus

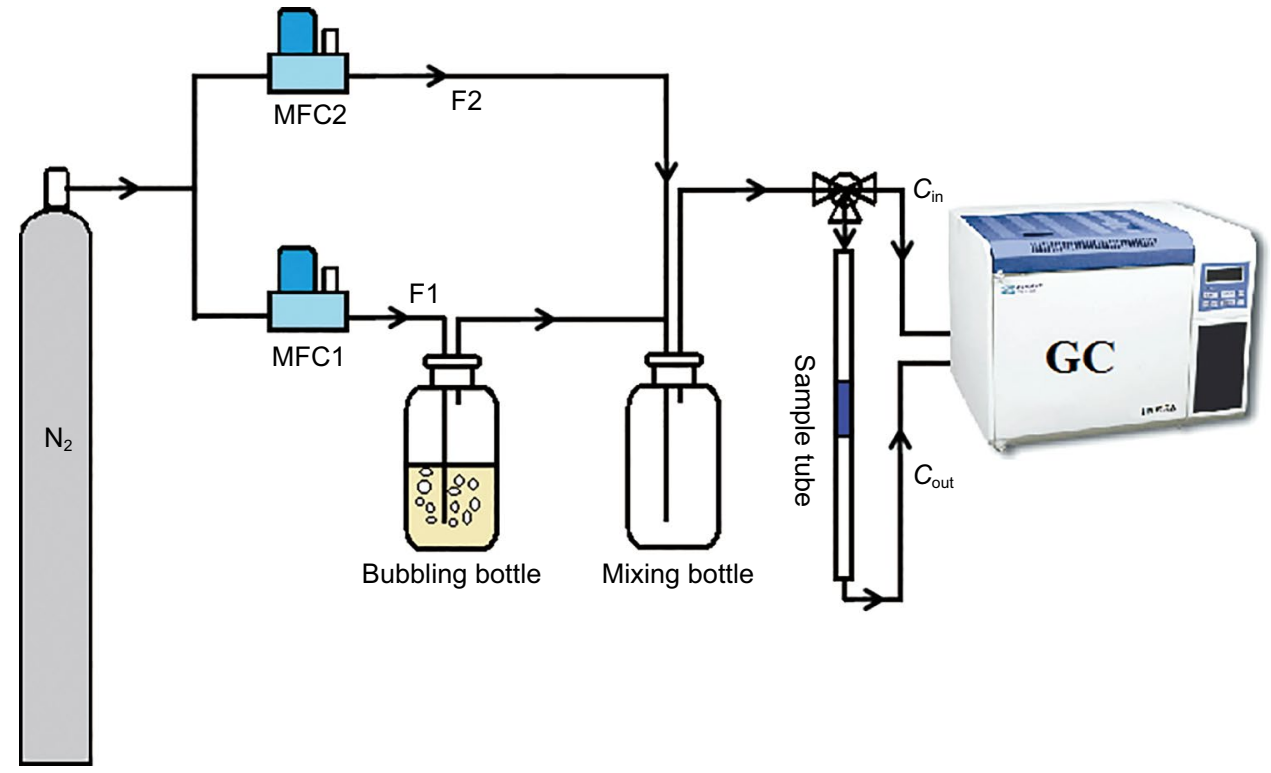

breakthrough curves obtained by plotting $C_{\text {out }, t} / C_{\text {in }}$ versus time. Adsorbent performance was estimated using three indicators: (1) the breakthrough time $t_{\mathrm{B}}(\mathrm{min})$, which is defined as the time taken for the ratio $C_{\mathrm{out}, l} / C_{\mathrm{in}}$ to be equal to 0.05 ; (2) the siloxane (L2 and/or D4) adsorption capacity at $t_{\mathrm{B}}$ ( $Q_{\mathrm{B}}, \mathrm{mg} / \mathrm{g}$ ); and (3) the siloxane (L2 and/or D4) adsorption capacity at saturation $\left(Q_{\mathrm{m}}, \mathrm{mg} / \mathrm{g}\right)$. This enabled $Q_{\mathrm{B}}$ and $Q_{\mathrm{m}}$ values for a semi-batch dynamic adsorption experiment, carried out using a continuous flow of gas and a fixed quantity of adsorbent, to be calculated using Eq. (1).

$Q_{t}=\frac{V_{\mathrm{q}} C_{\text {in }}}{m} \int_{0}^{t}\left(1-\frac{C_{\text {out }, t}}{C_{\text {in }}}\right) \mathrm{d} t$

where $V_{\mathrm{q}}$ is the gas flow rate $(\mathrm{L} / \mathrm{min}) ; m$ is the mass of the adsorbent $(\mathrm{g}) ; C_{\mathrm{in}}$ and $C_{\mathrm{out}, t}$ are the inlet and outlet siloxane concentration in the gas flow $(\mathrm{mg} / \mathrm{L})$, respectively; $t$ is the adsorption time, with integrated adsorption capacities $Q_{t}$ calculated for every $t$ value. $Q_{\mathrm{B}}$ was obtained when $t$ is equal $t_{\mathrm{B}}$, with $Q_{\mathrm{m}}$ calculated over the period from $t=0$ to the point of saturation $\left(C_{\mathrm{out}, t} / C_{\mathrm{in}} \approx 1\right)$.

\section{Results and discussion}

\subsection{Characterization of the physical properties of SG and Ac@SG}

The XRD patterns of SG and Ac@SG are shown in Fig. 2, with the Ac@SG sample showing identical diffraction

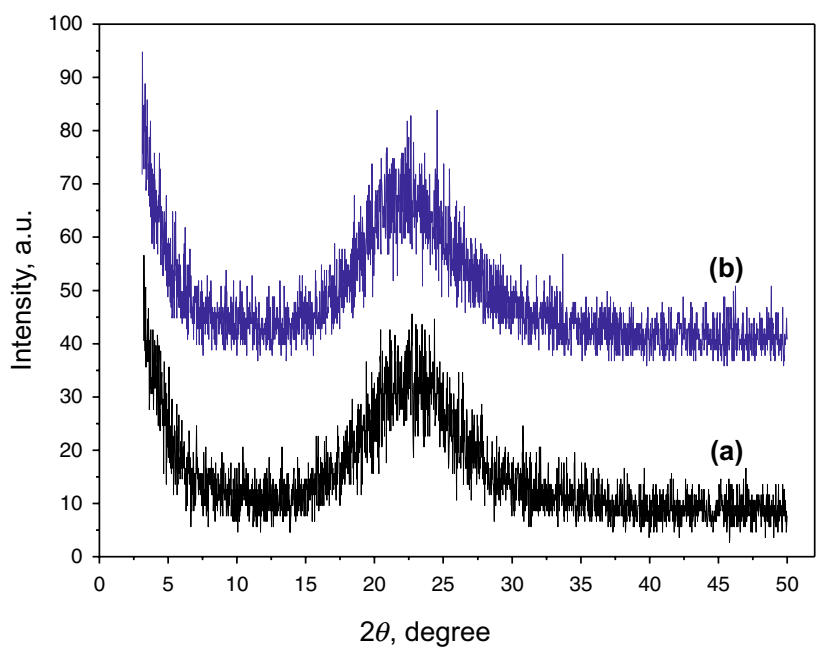

Fig. 2 XRD patterns of SG (a) and Ac@SG (b)

patterns to those for $\mathrm{SG}$, with no additional peaks for any other crystalline substances being present. This implies that acetylation occurs on the surface of the silica gel, with no modification of its skeleton having occurred. Comparison of the elemental composition of SG and Ac@SG using EDS confirmed the presence of carbon originating from the acetyl groups (Fig. 3). Comparison of the FT-IR spectra of the Ac@SG sample (Fig. 4b) with the FT-IR spectra of SG (Fig. 4a) revealed the presence of three additional well-defined bands at 2996, 1706 and $1379 \mathrm{~cm}^{-1}$. These absorbances were attributed to the $\mathrm{C}-\mathrm{H}$ stretching 

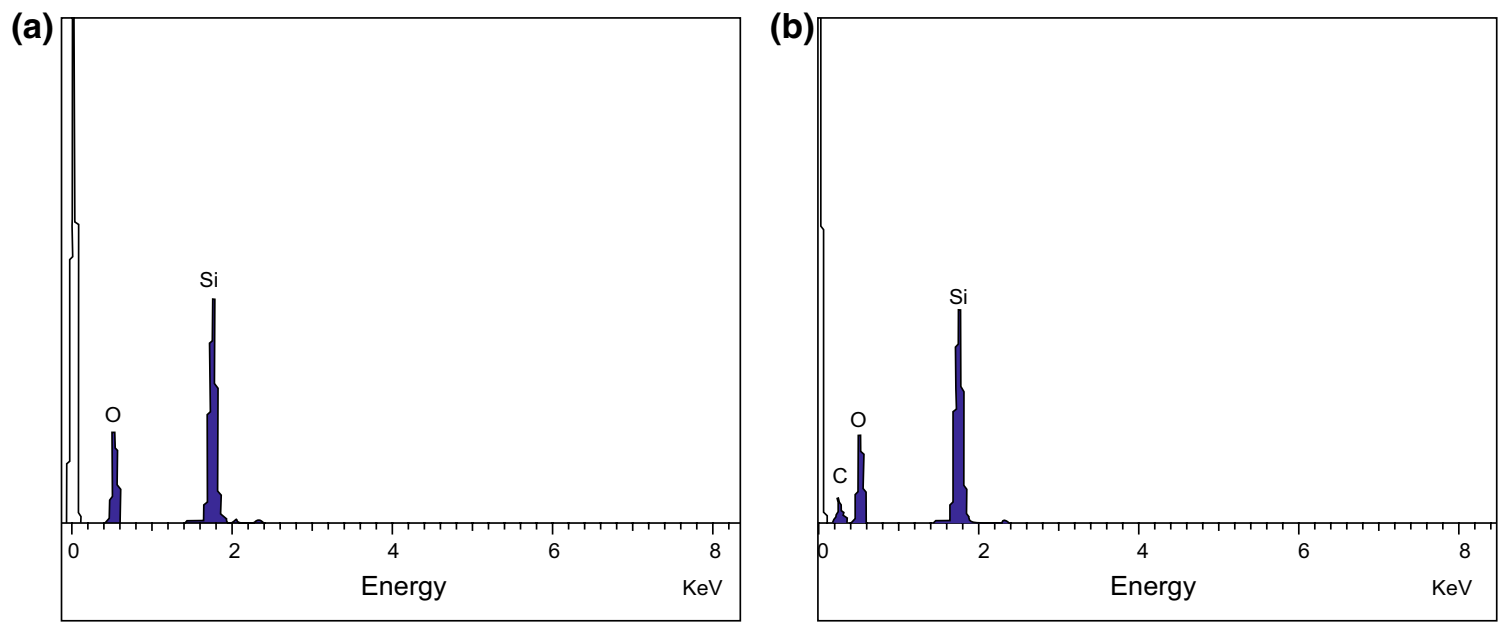

Fig. 3 EDS spectrum of SG (a) and Ac@SG (b)

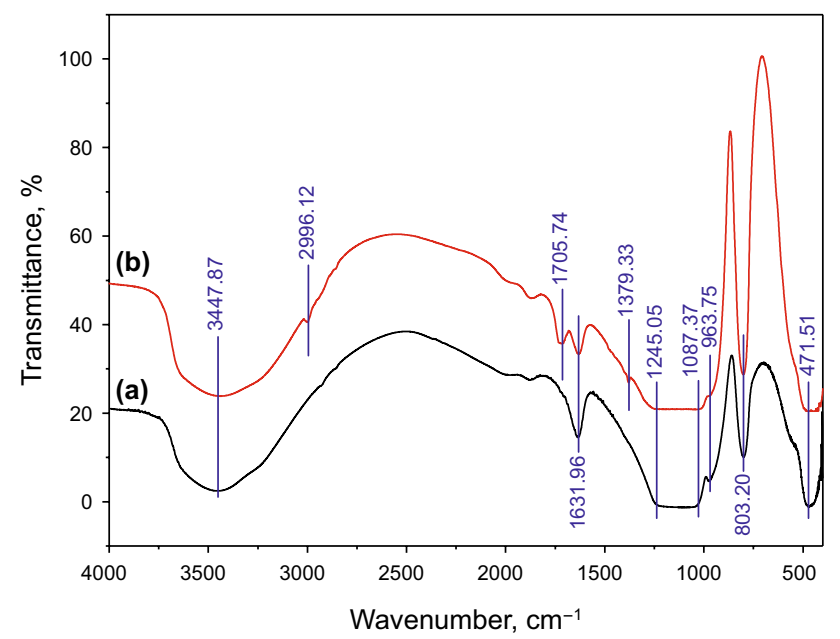

Fig. 4 FT-IR spectra of SG (a) and Ac@SG (b)

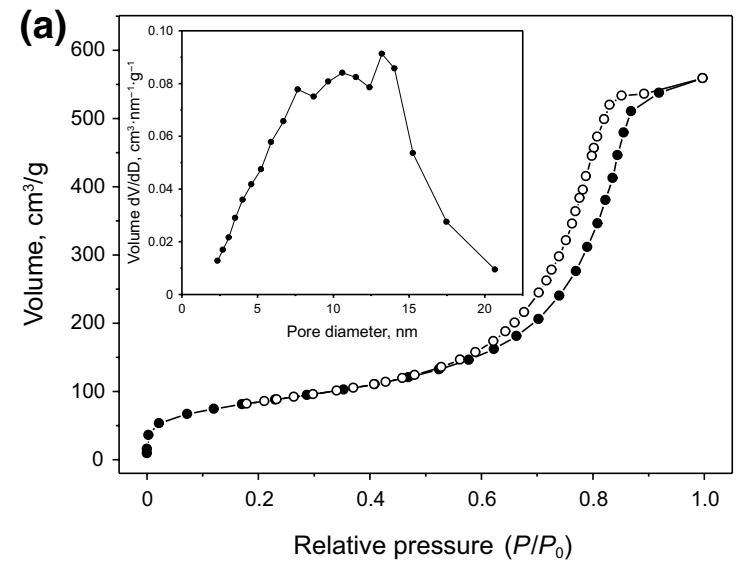

vibration of the $\mathrm{CH}_{3}$ group, the $\mathrm{C}=\mathrm{O}$ stretching vibration and the $\mathrm{C}-\mathrm{H}$ bending vibrations of $\mathrm{CH}_{3}$ groups of its acetyl groups (Pei and Ponec 1996; Mobaraki and Hemmateenejad 2011). A strong absorption at $3447 \mathrm{~cm}^{-1}$ was assigned to the $\mathrm{O}-\mathrm{H}$ stretching vibration and a peak at $1632 \mathrm{~cm}^{-1}$ assigned to the $\mathrm{O}-\mathrm{H}$ bending vibrations of surface silanol groups and adsorbed water molecules. A broadband at 1087-1245 $\mathrm{cm}^{-1}$ was attributed to the antisymmetric stretching vibration of $\mathrm{Si}-\mathrm{O}-\mathrm{Si}$ groups, with bands at 964 , 803 and $472 \mathrm{~cm}^{-1}$ assigned to the stretching and bending vibrations of $\mathrm{Si}-\mathrm{O}$ groups (Sui et al. 2016; Mota et al. 2017).

The adsorption properties of SG and Ac@SG were analyzed using a $\mathrm{N}_{2}$-BET method. $\mathrm{N}_{2}$ adsorption-desorption isotherms indicating that both samples exhibited a typical type IV isotherm (see Fig. 5 and Table 1). Hysteresis loop results and pore size distribution curves reveal that SG and Ac@SG

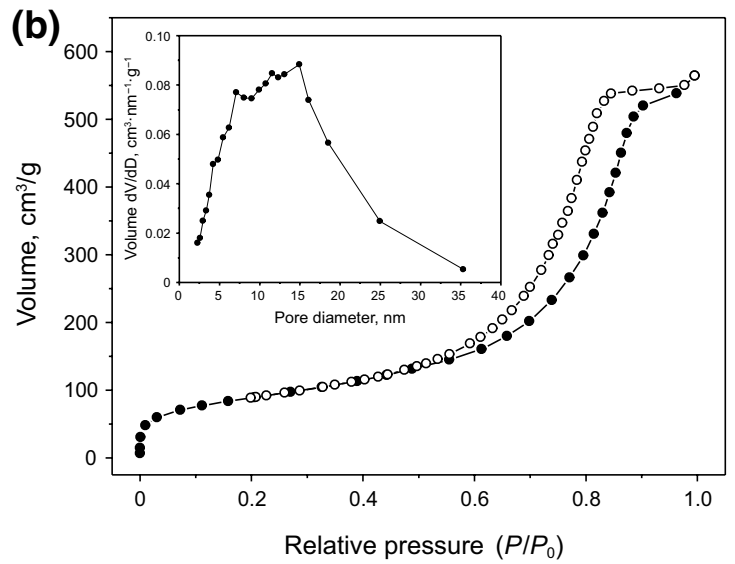

Fig. $5 \quad \mathrm{~N}_{2}$ adsorption-desorption isotherms and pore size distributions (inset) of SG (a) and Ac@ SG (b) 
Table 1 Texture parameters of SG and Ac@SG

\begin{tabular}{lllllll}
\hline Sample & \multicolumn{2}{l}{$\begin{array}{l}\text { Specific surface } \\
\text { area, } \mathrm{m}^{2} / \mathrm{g}\end{array}$} & & \multicolumn{2}{l}{ Pore volume, $\mathrm{cm}^{3} / \mathrm{g}$} & $\begin{array}{l}\text { Average pore } \\
\text { diameter, nm }\end{array}$ \\
\cline { 2 - 3 } & $S_{\text {BET }}$ & $S_{\text {micro,DR }}$ & & $V_{\text {micro, DR }}$ & $V_{\text {total }}$ & $d_{\text {BJH }}$ \\
\hline SG & 286 & 259 & & 0.13 & 0.74 & 10.1 \\
Ac@SG & 369 & 356 & & 0.16 & 0.86 & 13.8 \\
\hline
\end{tabular}

were meso-/microporous materials, with average pore diameters of 10.1 and $13.8 \mathrm{~nm}$, respectively. The specific surface area, micropore specific surface area, total pore volume and micropore volume of Ac@SG were all significantly greater than for SG, implying that the texture parameters of Ac@SG should be more favored for siloxane adsorption.

\subsection{Comparison of the adsorption properties of SG and Ac@SG}

Dynamic adsorption tests revealed that the breakthrough time $\left(t_{\mathrm{B}}\right)$ for Ac@SG was significantly greater than for SG for L2 and D4 adsorption (see Fig. 6 and Table 2), with $Q_{\mathrm{B}}$ values for Ac@SG of $282 \mathrm{mg} \mathrm{L} 2 / \mathrm{g}$ and 851 $\mathrm{mg} \mathrm{D} 4 / \mathrm{g}$, and corresponding to $Q_{\mathrm{m}}$ values for $\mathrm{SG}$ of 304 $\mathrm{mg} \mathrm{L2/g}$ and $916 \mathrm{mg} \mathrm{D} 4 / \mathrm{g}$, respectively. These results imply that adsorption of nonpolar siloxanes by Ac@SG is favored by the more hydrophobic acetyl groups present on its surface, which can be certified by a semiquantitative comparison in Washburn's method (shown in Fig.

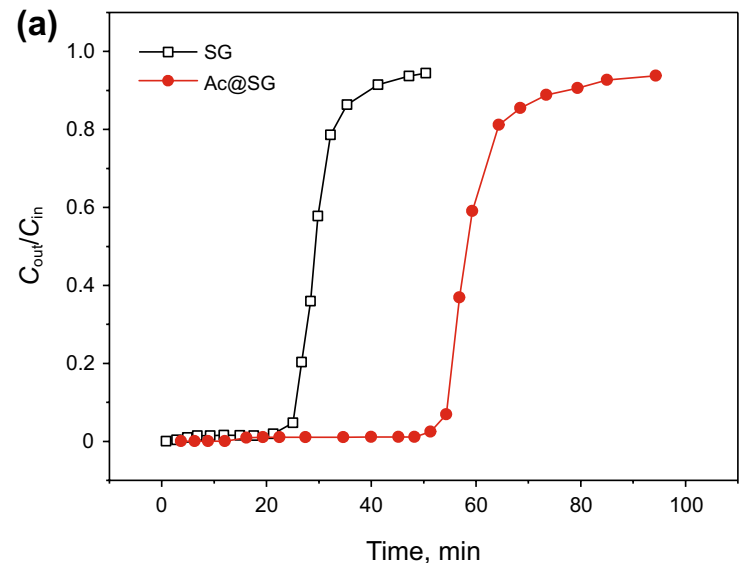

$\mathrm{S} 1$ in supplementary material). In addition, the reason of different adsorption results between D4 and L2 might be related to the nonpolar proportion and molecular weight of D4, which are both larger than that L2.

\subsection{Optimization of the synthesis of Ac@SG}

A series of optimization reactions revealed that the best conditions for preparing Ac@SG adsorbent with an optimal capacity for adsorbing siloxanes involved use of a 3:8 ratio of SG to acetic anhydride at $90{ }^{\circ} \mathrm{C}$ for $10 \mathrm{~h}$ (see Table 3 ).

\subsection{Influence of inlet concentration ( $\left.C_{\mathrm{in}}\right)$ on adsorption of Ac@SG}

The concentration of siloxanes present in different sources of landfill gases or biogas is variable; therefore, it was necessary to determine the breakthrough times $\left(t_{\mathrm{B}}\right)$ of the Ac@ $\mathrm{SG}$ adsorbent for different concentrations of siloxane. Various concentrations of simulated gas (Table 4, L2 or D4) were produced by regulating the gas flow rates of two mass flow controllers (MFC1 and MFC2), with $t_{\mathrm{B}}$ increasing for decreased inlet concentrations. The breakthrough times for Ac@SG were determined from curves correlating $C_{\text {in }}$ (L2 or D4) to $t_{\mathrm{B}}$ (Fig. 7) that enabled the influence of initial siloxane concentration on adsorption performance to be determined. The fitted data for L2 and D4 are shown in Fig. 7a, b, which exhibit correlation coefficients $\left(R^{2}\right)$ of 0.9993 and 0.9992 , respectively. Therefore, breakthrough times for these

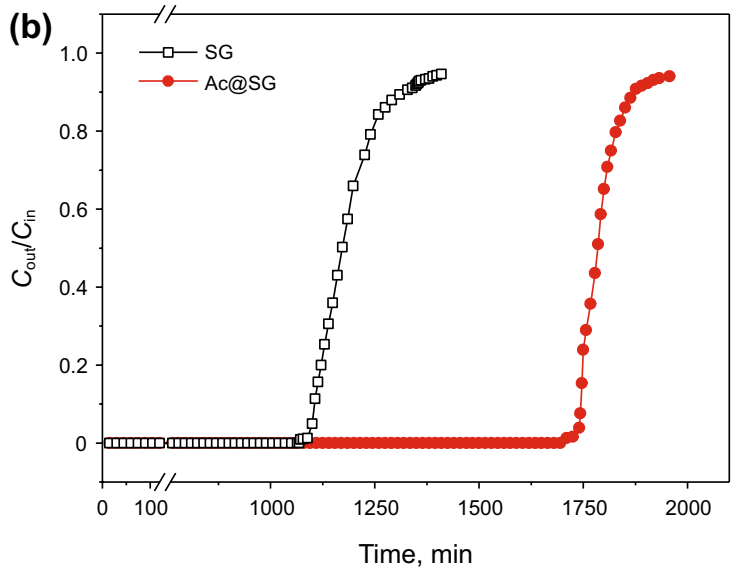

Fig. 6 Breakthrough curves of L2 (a) and D4 (b)

Table 2 Adsorption comparison of SG and Ac@SG for L2 and D4

\begin{tabular}{|c|c|c|c|c|c|c|}
\hline \multirow[t]{2}{*}{ Adsorbent } & \multicolumn{2}{|c|}{$t_{\mathrm{B}}, \min$} & \multicolumn{2}{|c|}{$Q_{\mathrm{B}}, \mathrm{mg} / \mathrm{g}$} & \multicolumn{2}{|c|}{$Q_{\mathrm{m}}, \mathrm{mg} / \mathrm{g}$} \\
\hline & L2 & D4 & L2 & D4 & L2 & D4 \\
\hline SG & 25.0 & 1100 & 105 & 538 & 136 & 602 \\
\hline Ac@SG & 54.3 & 1740 & 282 & 851 & 304 & 916 \\
\hline
\end{tabular}

Mass of adsorbents $=0.8 \mathrm{~g}, C_{\mathrm{in}}: \mathrm{L} 2=83.8 \mathrm{mg} / \mathrm{L}, \mathrm{D} 4=7.9 \mathrm{mg} / \mathrm{L}$, Gas flow rate $=50 \mathrm{~mL} / \mathrm{min}$ 
Table 3 Preparation conditions of Ac@SG and the adsorption indicators for L2

\begin{tabular}{lllllll}
\hline Entry & $\begin{array}{l}\text { Temperature, } \\
{ }^{\circ} \mathrm{C}\end{array}$ & Time, & Ratio $^{\mathrm{a}}$ & $t_{\mathrm{B}}, \mathrm{min}$ & $Q_{\mathrm{B}}, \mathrm{mg} / \mathrm{g}$ & $Q_{\mathrm{m}}, \mathrm{mg} / \mathrm{g}$ \\
\hline 1 & $\begin{array}{l}\text { Room tem- } \\
\text { perature }\end{array}$ & 6 & $3: 7$ & 34.3 & 178 & 196 \\
2 & 50 & 6 & $3: 7$ & 36.5 & 189 & 208 \\
3 & 70 & 6 & $3: 7$ & 38.8 & 201 & 220 \\
4 & 90 & 6 & $3: 7$ & 41.8 & 217 & 236 \\
5 & 110 & 6 & $3: 7$ & 41.8 & 2177 & 236 \\
6 & 90 & 5 & $3: 7$ & 39.1 & 203 & 223 \\
7 & 90 & 7 & $3: 7$ & 43.9 & 228 & 248 \\
8 & 90 & 8 & $3: 7$ & 45.8 & 238 & 258 \\
9 & 90 & 9 & $3: 7$ & 48.2 & 250 & 271 \\
10 & 90 & 10 & $3: 7$ & 51.1 & 265 & 286 \\
11 & 90 & 12 & $3: 7$ & 51.1 & 265 & 286 \\
12 & 90 & 10 & $3: 5$ & 38.9 & 202 & 223 \\
13 & 90 & 10 & $3: 6$ & 45.9 & 238 & 260 \\
14 & 90 & 10 & $3: 8$ & 54.3 & 282 & 304 \\
15 & 90 & 10 & $3: 9$ & 54.3 & 282 & 304 \\
\hline
\end{tabular}

$\mathrm{M}_{\mathrm{Ac} @ \mathrm{SG}}=0.8 \mathrm{~g}, C_{\mathrm{in}, \mathrm{L} 2}=83.8 \mathrm{mg} / \mathrm{L}$, gas flow rate $=50 \mathrm{~mL} / \mathrm{min}$

${ }^{\mathrm{a}}$ The mass ratio of silica gel to anhydride
Table 4 Influence of the L2 and D4 inlet concentration

\begin{tabular}{llllll}
\hline Entry & \multicolumn{2}{l}{$\mathrm{L} 2$} & & $\mathrm{D} 4$ \\
\cline { 2 - 3 } \cline { 5 - 6 } & $C_{\text {in }}, \mathrm{mg} / \mathrm{L}$ & $t_{\mathrm{B}}, \mathrm{min}$ & & $C_{\text {in }}, \mathrm{mg} / \mathrm{L}$ & $t_{\mathrm{B}}, \min$ \\
\hline 1 & 83.8 & 54.3 & & 7.9 & 215 \\
2 & 73.7 & 61.4 & & 6.3 & 269 \\
3 & 63.8 & 70.6 & & 4.7 & 358 \\
4 & 47.4 & 86.2 & & 4.0 & 430 \\
5 & 38.3 & 99.3 & & 3.2 & 537 \\
6 & 31.0 & 116 & & - \\
7 & 23.1 & 150 & & - & - \\
8 & 17.9 & 182 & - & - \\
\hline
\end{tabular}

$\mathrm{M}_{\mathrm{Ac} @ \mathrm{SG}, \mathrm{L} 2}=0.8 \mathrm{~g}, \mathrm{M}_{\mathrm{Ac} @ \mathrm{SG}, \mathrm{D} 4}=0.1 \mathrm{~g}$

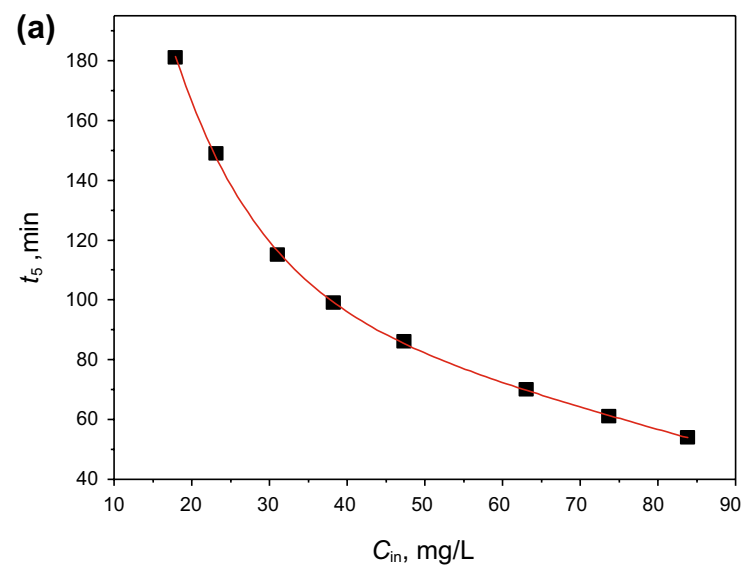

supports can be predicted for L2 and D4 using Eqs. (2) and (3), thus enabling their results which are used to provide data for their industrial use.

$$
\begin{aligned}
& t_{\mathrm{B}, \mathrm{L} 2}=398.0 \times \mathrm{e}^{-\frac{C_{\mathrm{in}}}{11.3}}+1.5 \times 10^{6} \times \mathrm{e}^{-\frac{C_{\text {in }}}{2.2 \times 10^{6}}}-1.5 \times 10^{6} \\
& t_{\mathrm{B}, \mathrm{D} 4}=1361.4 \times \mathrm{e}^{-0.4 \times C_{\text {in }}}+164.0
\end{aligned}
$$

\subsection{Influence of temperature on adsorption properties of Ac@SG}

The influence of temperature on the adsorption of Ac@SG for L2 and D4 is shown in Table 5, with $t_{\mathrm{B}}$ and $Q_{\mathrm{B}}$ values

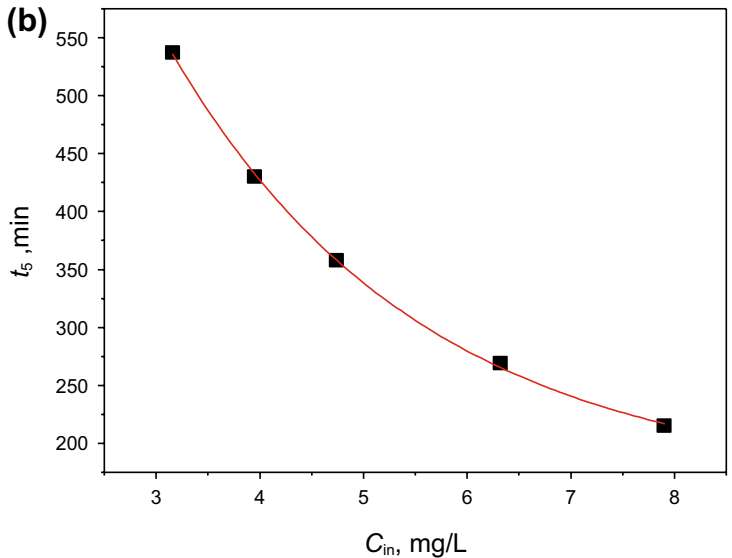

Fig. 7 Relationship between breakthrough time $\left(t_{\mathrm{B}}\right)$ and the inlet concentrations $\left(C_{\mathrm{in}}\right)$ of L2 (a) and D4 (b) 
Table 5 Influence of the temperature on the adsorption of L2 and D4

\begin{tabular}{|c|c|c|c|c|c|c|}
\hline \multirow[t]{2}{*}{ Entry } & \multicolumn{4}{|l|}{$\mathrm{L}^{\mathrm{a}}$} & \multicolumn{2}{|l|}{$\mathrm{D} 4^{\mathrm{b}}$} \\
\hline & $\begin{array}{l}\text { Tempera- } \\
\text { ture, }{ }^{\circ} \mathrm{C}\end{array}$ & $t_{\mathrm{B}}, \min$ & $Q_{\mathrm{B}}, \mathrm{mg} / \mathrm{g}$ & $\begin{array}{l}\text { Tempera- } \\
\text { ture, }{ }^{\circ} \mathrm{C}\end{array}$ & $t_{\mathrm{B}}, \min$ & $Q_{\mathrm{B}}, \mathrm{mg} / \mathrm{g}$ \\
\hline 1 & 0 & 121 & 628 & 20 & 215 & 842 \\
\hline 2 & 10 & 82.1 & 426 & 30 & 134 & 524 \\
\hline 3 & 25 & 54.3 & 282 & 40 & 85.9 & 336 \\
\hline 4 & 45 & 33.2 & 172 & 50 & 51.7 & 202 \\
\hline 5 & 60 & 25.9 & 134 & 60 & 35.5 & 139 \\
\hline
\end{tabular}

The amount of adsorbent is shown in Table 4

${ }^{\mathrm{a}} C_{\text {in, L2 }}=83.8 \mathrm{mg} / \mathrm{L} ;{ }^{\mathrm{b}} C_{\text {in, D } 4}=7.9 \mathrm{mg} / \mathrm{L}$
Table 6 Influence of the adsorbent bed height and masses on the adsorption of L2 and D4

\begin{tabular}{llllll}
\hline Entry $^{\mathrm{a}}$ & Ac@SG, & $\begin{array}{l}\text { Bed height, } \\
\mathrm{mm}\end{array}$ & $t_{\mathrm{B}}, \mathrm{min}$ & $\begin{array}{l}\text { Total } \\
\text { adsorbed } \\
\text { amount, } \mathrm{mg}\end{array}$ & $Q_{\mathrm{B}}, \mathrm{mg} / \mathrm{g}$ \\
\hline 1 & 0.2 & 10.0 & 13.4 & 51.1 & 278 \\
2 & 0.4 & 20.0 & 26.9 & 104 & 279 \\
3 & 0.6 & 30.0 & 40.5 & 159 & 280 \\
4 & 0.8 & 40.0 & 54.3 & 214 & 282 \\
5 & 0.1 & 5.0 & 215 & 74.1 & 842 \\
6 & 0.3 & 15.0 & 647 & 230 & 843 \\
7 & 0.5 & 25.0 & 1080 & 391 & 845 \\
8 & 0.8 & 40.0 & 1741 & 629 & 851 \\
\hline
\end{tabular}

$C_{\text {in, } \mathrm{L} 2}=83.8 \mathrm{mg} / \mathrm{L} ; C_{\text {in, D4 }}=7.9 \mathrm{mg} / \mathrm{L}$

${ }^{\mathrm{a}}$ The data of entries (1-4) were L2, and others were D4

greater at lower temperatures, which means that the adsorption performance of Ac@SG is better at lower temperatures than that at higher temperatures. These results are in accordance with the results of Sigot et al. (2014), with the exothermic micropore adsorption and hydrophobic effects of the meso-/micro-porous skeletons and acetyl groups of Ac@SG resulting in good adsorption properties at lower temperatures.

\subsection{Influence of bed height and mass of Ac@SG adsorbent}

Dynamic adsorption tests were performed using different masses of Ac@SG in order to explore the combined influence of bed height and quantity of adsorbent on the efficiency of siloxane removal. As expected, increasing adsorbent bed height resulted in breakthrough times being delayed (Table $6, t_{\mathrm{B}}$, entries $1-4$ or $5-8$ ), with the total amount of L2 and D4 adsorbed found to be directly proportional to the mass of Ac@SG used. These results indicate that $Q_{\mathrm{B}}$ was not significantly affected by the adsorbent bed height (Ac@ SG mass) during the experiment process (see Table 6), with adsorption capacity range of 278-282 mg L2/g Ac@SG and 842-851 mg D4/g Ac@SG, respectively. These adsorption values mean that Ac@SG can absorb siloxanes at significantly lower concentration levels than conventional silica gel adsorbents (Matsui and Imamura 2010; Schweigkofler and Niessner 2001; Oshita et al. 2010).

\subsection{Influence of the presence of water on Ac@SG adsorbent}

Biogas is usually saturated with water at digester or landfill outlets (Sigot et al. 2014); therefore, the influence of water on the ability of silica gel (a desiccant) to adsorb siloxanes was evaluated. The ability of Ac @SG to remove L2 and D4 from dry and moist gas (RH of 70\%) is shown in Fig. 8, with water having no significant effect on the ability of Ac@ SG to remove L2 and D4. This phenomenon is likely to be due to the presence of hydrophobic acetyl groups on the surface of Ac@SG which reduced its ability to absorb water. Therefore, Ac@SG has a better affinity for L2 and D4 than water, meaning that Ac@SG can be used as an adsorbent for siloxanes from wet biogas sources.

\subsection{Thermal regeneration}

The thermal regeneration and reusability of a used Ac@SG sample that had been employed for $\mathrm{L} 2$ adsorption were then assessed by desorbing it at $110{ }^{\circ} \mathrm{C}$ for $2 \mathrm{~h}$ and then reusing it as an adsorbent in consecutive siloxane adsorption experiments, under the same conditions. Adsorption results revealed that breakthrough times remained between $48 \mathrm{~min}$ to 54 min, even after the same Ac@ @S sample was reused for five cycles of siloxane adsorption (see Fig. 9). 

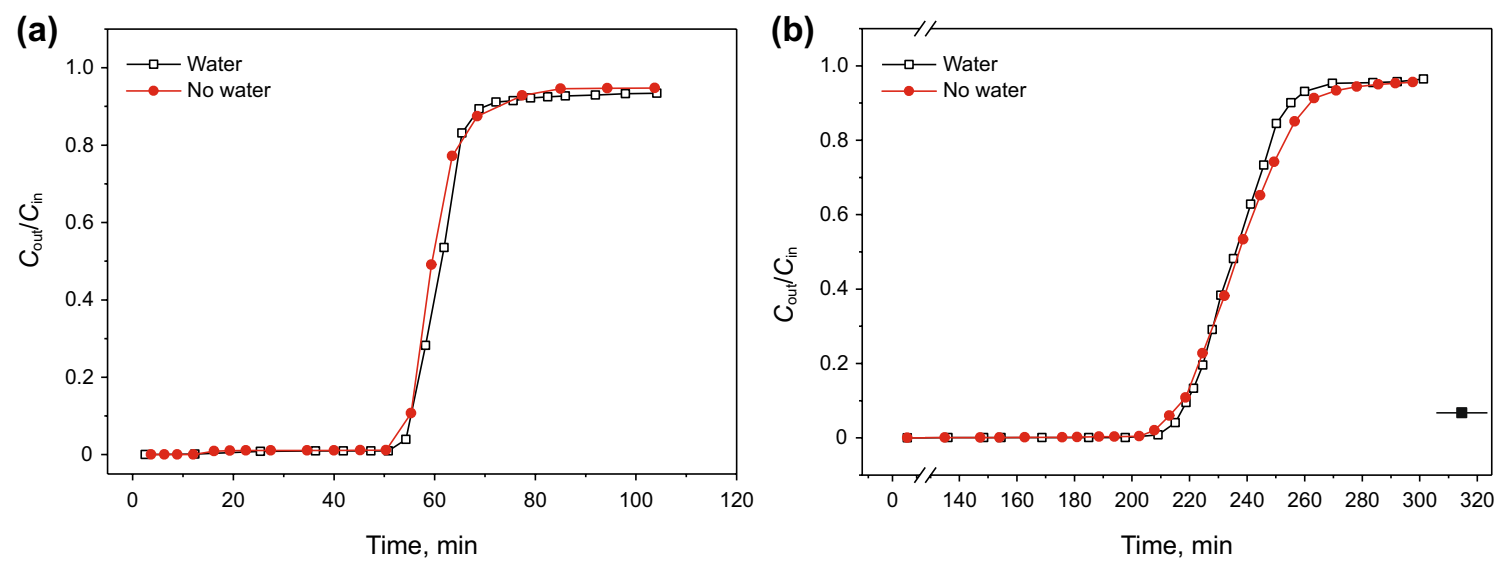

Fig. 8 Influence of the presence of water on the adsorption of L2 (a) and D4 (b)

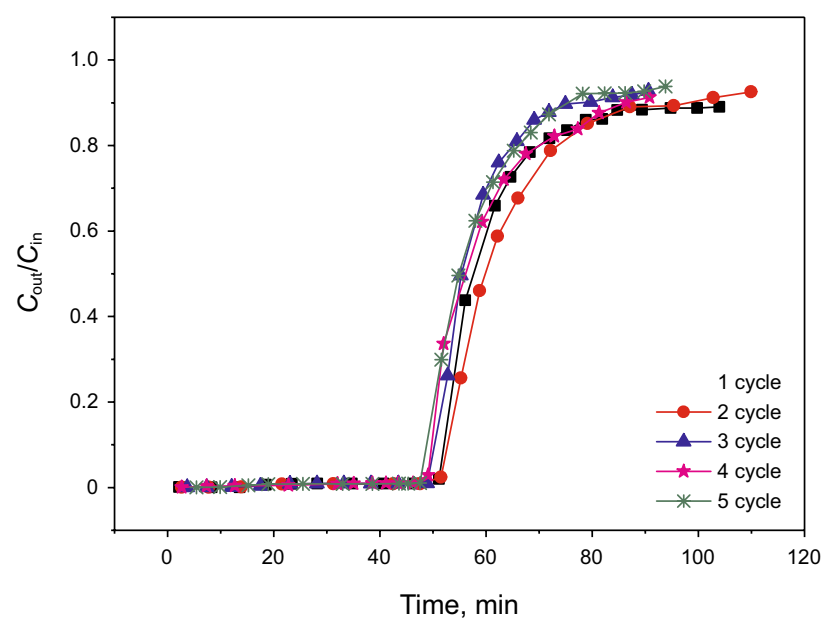

Fig. 9 Adsorption breakthrough curves for L2 of the regenerated Ac@SG

\section{Conclusions}

Acetylated silica gel Ac@SG has been synthesized via treatment of microporous silica gel (SG) with acetic anhydride. Its meso-/microporous structure and hydrophobic surface exhibited better adsorption properties for siloxanes than simple SG. Dynamic adsorption experiments revealed that low temperatures and deep adsorbent beds of Ac@SG gave the best siloxane adsorption levels, with the presence of water having no significant effect on their performance. This Ac@ SG adsorbent could be easily regenerated for reuse by heating at $110{ }^{\circ} \mathrm{C}$, with its adsorption capacity for siloxanes remaining relatively constant when it was recycled in consecutive dynamic adsorption experiments.
Acknowledgements We are grateful for the financial support from the National Natural Science Foundation of China (21677046) and the Natural Science Foundation of Hebei Province (B2017205146).

Open Access This article is distributed under the terms of the Creative Commons Attribution 4.0 International License (http://creativeco mmons.org/licenses/by/4.0/), which permits unrestricted use, distribution, and reproduction in any medium, provided you give appropriate credit to the original author(s) and the source, provide a link to the Creative Commons license, and indicate if changes were made.

\section{References}

Ahmed SA. Optimization and application of solid phase extraction of $\mathrm{Cu}$ (II) from aqueous solutions using new environmentally friendly modification of silica gel. J Environ Chem Eng. 2014;2:1713-21. https://doi.org/10.1016/j.jece.2014.06.011.

Ajhar M, Travesset M, Yüce S, et al. Siloxane removal from landfill and digester gas - A technology overview. Bioresour Technol. 2010;101:2913-23. https://doi.org/10.1016/j.biort ech.2009.12.018.

Allen MR, Braithwaite A, Hills CC. Trace organic compounds in landfill gas at seven U.K. Waste Disposal Sites. Environ Sci Technol. 1997;31:1054-61. https://doi.org/10.1021/es9605634.

An F, Gao B, Feng X. Adsorption of 2,4,6-trinitrotoluene on a novel adsorption material PEI/SiO . J Hazard Mater. 2009;166:757-61. https://doi.org/10.1016/j.jhazmat.2008.11.116.

Çimen A, Karakuş E, Bilgiç A. Chemical modification of silica gel with 4,4'-((1Z,8Z)-2,5,8-triazanona-1,8-diene-1,9-diyl) diphenol and applications to chromium $\mathrm{Cr}(\mathrm{VI})$ ions in industrial wastewaters. Desalin Water Treat. 2015;57:7219-31. https://doi. org/10.1080/19443994.2015.1014854.

Damja RI, Eaborn C. Preparation and reactions of some sterically hindered silanols, including [tris(trimethylsilyl)methyl] silanetriol. J Organomet Chem. 1985;290:267-75. https://doi. org/10.1016/0022-328x(85)87289-2.

De Arespacochaga N, Valderrama C, Mesa C, et al. Biogas deep clean-up based on adsorption technologies for solid oxide fuel cell applications. Chem Eng J. 2014;255:593-603. https://doi. org/10.1016/j.cej.2014.06.072. 
Devia CR, Subrenat A. Absorption of a linear (L2) and a cyclic (D4) siloxane using different oils: application to biogas treatment. Environ Technol. 2013;34(23):3117-27. https://doi.org/10.1080/09593 330.2013.804588.

Dewil R, Appels L, Baeyens J. Energy use of biogas hampered by the presence of siloxanes. Energy Convers Manage. 2006;47:171122. https://doi.org/10.1016/j.enconman.2005.10.016.

Eaborn C, Lickiss PD, Taylor AD. Reactions of the sterically hindered organosilicon diol $\left(\mathrm{Me}_{3} \mathrm{Si}\right)_{2} \mathrm{C}\left(\mathrm{SiMe}_{2} \mathrm{OH}\right)_{2}$ and some of its derivatives. J Organomet Chem. 1988;340:283-92. https://doi. org/10.1016/0022-328x(88)80022-6.

Jafari T, Jiang T, Zhong W, et al. Modified mesoporous silica for efficient siloxane capture. Langmuir. 2016;32(10):2369-78. https:// doi.org/10.1021/acs.langmuir.5b04357.

Jiang T, Zhong W, Jafari T, et al. Siloxane D4 adsorption by mesoporous aluminosilicates. Chem Eng J. 2016;289:356-64. https://doi.org/10.1016/j.cej.2015.12.094.

Kajolinna T, Aakko-Saksa P, Roine J, et al. Efficiency testing of three biogas siloxane removal systems in the presence of D5, D6, limonene and toluene. Fuel Process Technol. 2015;139:242-7. https://doi.org/10.1016/j.fuproc.2015.06.042.

Koner S, Pal A, Adak A. Adsorption of 2,4-D-herbicide from water environment on modified silica gel factory waste. Water Environ Res. 2013;85:2147-56. https://doi.org/10.2175/106143013X 13736496909310.

Kougias PG, Angelidaki I. Biogas and its opportunities-A review. Front Env Sci Eng. 2018;12:1-13. https://doi.org/10.1007/s1178 3-018-1037-8.

Lee I, Rittmann BE. Using focused pulsed technology to remove siloxane from municipal sewage sludge. J Environ Eng. 2016;142:040150561-6. https://doi.org/10.1061/(ASCE)EE.19437870.0000975 .

Machin WD, Golding PD. Adsorption of $n$-butane on silica gel. Langmuir. 1987;3:346-9. https://doi.org/10.1021/la00075a011.

Matsui T, Imamura S. Removal of siloxane from digestion gas of sewage sludge. Bioresour Technol. 2010;101:S29-32. https://doi. org/10.1016/j.biortech.2009.05.037.

Mobaraki N, Hemmateenejad B. Structural characterization of carbonyl compounds by IR spectroscopy and chemometrics data analysis. Chemometr Intell Lab. 2011;109:171-7. https://doi.org/10.1016/j. chemolab.2011.08.011
Mota TRL, de Oliveira MAP, Nunes EHM, et al. Simple process for preparing mesoporous sol-gel silica adsorbents with high water adsorption capacities. Micropor Mesopor Mat. 2017;253:177-82. https://doi.org/10.1016/j.micromeso.2017.07.010.

Oshita K, Ishihara Y, Takaoka M, et al. Behaviour and adsorptive removal of siloxanes in sewage sludge biogas. Water Sci Technol. 2010;61:2003-12. https://doi.org/10.2166/wst.2010.101.

Pei ZF, Ponec V. On the intermediates of the acetic acid reactions on oxides: an IR study. Appl Surf Sci. 1996;103:171-82. https://doi. org/10.1016/0169-4332(96)00453-9.

Schweigkofler M, Niessner R. Removal of siloxanes in biogases. J Hazard Mater. 2001;B83:183-96. https://doi.org/10.1016/S0304 -3894(00)00318-6.

Sigot L, Ducom G, Benadda B, et al. Adsorption of octamethylcyclotetrasiloxane on silica gel for biogas purification. Fuel. 2014;135:205-9. https://doi.org/10.1016/j.fuel.2014.06.058.

Sigot L, Ducom G, Germain P. Adsorption of octamethylcyclotetrasiloxane (D4) on silica gel(SG): retention mechanism. Micropor Mesopor Mat. 2015;213:118-24. https://doi.org/10.1016/j.micro meso.2015.04.016.

Sui DP, Chen HX, Li DW. Sol-gel-derived thiocyanato-functionalized silica gel sorbents for adsorption of Fe(III) ions from aqueous solution: kinetics, isotherms and thermodynamics. J Sol-Gel Sci Technol. 2016;80:504-13. https://doi.org/10.1007/s1097 1-016-4092-2.

Sui H, An P, Li X, et al. Removal and recovery of $o$-xylene by silica gel using vacuum swing adsorption. Chem Eng J. 2017a;316:232-42. https://doi.org/10.1016/j.cej.2017.01.061.

Sui H, Liu H, An P, et al. Application of silica gel in removing high concentrations toluene vapor by adsorption and desorption process. J Taiwan Inst Chem E. 2017b;74:218-24. https://doi. org/10.1016/j.jtice.2017.02.019.

Turkin AA, Dutka M, Vainchtein D, et al. Deposition of $\mathrm{SiO}_{2}$ nanoparticles in heat exchanger during combustion of biogas. Appl Energy. 2014;113:1141-8. https://doi.org/10.1016/j.apene rgy.2013.08.068.

Uruş S, Purtaş S, Ceyhan G, et al. Solid phase extraction of $\mathrm{Pb}(\mathrm{II})$, $\mathrm{Cu}(\mathrm{II}), \mathrm{Cd}(\mathrm{II})$ and $\mathrm{Cr}(\mathrm{III})$ with syringe technique using novel silica-supported bis(diazoimine) ligands. Chem Eng J. 2013;220:420-30. https://doi.org/10.1016/j.cej.2013.01.037. 